\title{
Magnetic and Structural Properties of $\mathrm{MnBi}_{1-\mathrm{x}} \mathrm{Ti}_{\mathrm{x}}$ Alloys
}

\author{
Suyin Zhang, Pengyue Zhang*, HuanChang Jiang, Yaojun Shi, Nengjun Yu, and Hongliang Ge \\ Magnetism Key Laboratory of Zhejiang Province, China Jiliang University, Hangzhou 310018, China
}

(Received 25 December 2013, Received in final form 29 May 2014, Accepted 11 June 2014)

\begin{abstract}
$\mathrm{MnBi}_{1-\mathrm{x}} \mathrm{Ti}_{\mathrm{x}}(\mathrm{x}=\mathbf{0}, 0.4,0.7,1)$ alloys were prepared by arc-melting, followed by heat treatment. X-ray diffraction (XRD) and vibrating sample magnetometer (VSM) were used to measure and investigate the phase structure and magnetic properties. The temperature dependent magnetization curves indicate that the phase transitions between LTP and HTP MnBi occur with heating or cooling in $\mathrm{MnBi}_{1-\mathrm{x}} \mathrm{Ti}_{\mathbf{x}}(\mathbf{x} \leq \mathbf{0 . 7})$ samples. However, MnTi samples are in $\mathrm{Mn}_{2} \mathrm{Ti}$ single-phase, with very low magnetic properties. Furthermore, the coercivity exhibits a positive temperature coefficient. The results show that the optimal content of $T i$ for the coercivity of $\mathrm{MnBi}_{1-\mathrm{x}} \mathrm{Ti}_{\mathrm{x}}$ alloy is $x=0.4$. For $\mathrm{MnBi}$ sample, the coercivity reaches a maximum value of $1.13 \mathrm{~T}$ at $550 \mathrm{~K}$. However, the remanence and energy product show apparent decrease with the addition of $T i$ in $\mathrm{MnBi}_{1-\mathrm{x}} \mathrm{Ti}_{\mathrm{x}}$ alloys.
\end{abstract}

Keywords : MnBi, phase transition, magnetic properties

\section{Introduction}

$\mathrm{MnBi}$ is a ferromagnetic intermetallic compound with NiAs-type hexagonal crystal structure. It has attracted research interest, mainly due to its unusually large magnetic anisotropy of the low-temperature phase (LTP) [1, 2], and the excellent magneto-optical properties of the quenched high-temperature phase (QHTP) [3]. It is remarkable that the coercivity of the LTP exhibits a positive temperature coefficient, and is much larger than that of Nd-Fe-B magnets at high temperature [4-6]. Therefore, MnBi has good potential to be used in high temperature circumstances [7]. However, the segregation of Mn during peritectic reaction makes it difficult to obtain single-phase $\mathrm{MnBi}$ by conventional techniques, such as high temperature sintering and induction melting, which also makes it difficult to study the magnetic properties of MnBi. Many efforts have been made to produce single-phase MnBi. Yoshida et al. [8] prepared the MnBi magnet with about 90 wt.\% LTP by zone-arc-melting under $\mathrm{He}$ atmosphere, followed by heat treatment. The Curie temperature was measured at $633 \mathrm{~K}$. Furthermore, fine powders obtained by grinding the strongly orientated bulk possess a large coercivity of $0.7 \mathrm{~T}$, and this large coercivity is considered to be due to the large crystalline

(C)The Korean Magnetics Society. All rights reserved.

*Corresponding author: Tel: +86 57187676238

Fax: +86 57187676238, e-mail: zhang_pengyue@cjlu.edu.cn anisotropy of the particles in the single domain state. It is verified that doping with transitional elements, such as Ti, $\mathrm{Zr}, \mathrm{Cu}$ etc, evidently promotes crystallization and refines grain sizes in the metastable disordered structure, and hence results in a significant remanence enhancement and high performance $[9,10]$. The intrinsic coercivity ${ }_{\mathrm{i}} H_{\mathrm{c}}$ of 9797 Oe has been obtained for the $\mathrm{SmCo}_{7.1} \mathrm{Ti}_{0.4}$ as-spun ribbons [11]. Hono et al. [12] reported that the addition of 4 at.\% Ti significantly modified the solidification path, by suppressing the formation of $\mathrm{Nd}_{2} \mathrm{Fe}_{23} \mathrm{~B}_{3}$ phase and promoting the formation of $\mathrm{Nd}_{2} \mathrm{Fe}_{14} \mathrm{~B}$ phase, subsequently resulting in a improvement in the coercivity and energy product. Also, Harrison et al. [13] reported that the coaddition of $\mathrm{Ti}$ and $\mathrm{C}$ in nanocomposite alloys could refine the nanocomposite microstructure, and finally enhanced coercivity. Up to now the addition of $\mathrm{Ti}$ in the intermetallic compound $\mathrm{MnBi}$ has not been reported.

In this article, titanium substitutes for bismuth, with the chemical formula $\mathrm{MnBi}_{1-\mathrm{x}} \mathrm{Ti}_{\mathrm{x}}(\mathrm{x}=\mathrm{x}=0,0.4,0.7$, and 1) in the intermetallic structure. The temperature dependent magnetization (350-700 K) and demagnetization (100-600 $\mathrm{K})$ curves are measured by vibrating sample magnetometer (VSM). The purpose of this investigation is to detect the effect on the phase formation structure and magnetic properties in $\mathrm{MnBi}$ alloy, by the substitution of $\mathrm{Ti}$ for $\mathrm{Bi}$. This is helpful for further investigations into $\mathrm{MnBi}_{1-\mathrm{x}} \mathrm{Ti}_{\mathrm{x}}$ systems. 


\section{Experimental}

$\mathrm{MnBi}_{1-\mathrm{x}} \mathrm{Ti}_{\mathrm{x}}$ ingots were prepared by arc-melting with high purity manganese, bismuth and titanium (both of $99.99 \%$ purity) in atomic ratios. Heat treatment was performed in a vacuum for 30 minutes, at a fixed temperature ranging from 380 to $600 \mathrm{~K}$, and the sample was finally transformed into the LTP. X-ray diffraction (XRD) measurements were made at room temperature to characterize the samples phase structure, using Rigaku diffractometer with $\mathrm{CuKa}$ radiation. Temperature dependent magnetization measurements were made using a Lakeshore 7407 vibrating sample magnetometer with high temperature oven, which were used to measure the magnetization hysteresis loops of the magnet at different temperature (100 K-600 K).

\section{Results and Discussion}

The X-ray diffraction (XRD) patterns of $\mathrm{MnBi}_{1-\mathrm{x}} \mathrm{Ti}_{\mathrm{x}}$ (x $=0,0.4,0.7$ and 1) samples are shown in Figure 1 . Comparison reveals that the positions and intensities of the peaks are different. This indicates that $\mathrm{MnBi}_{1-\mathrm{x}} \mathrm{Ti}_{\mathrm{x}}$ $(\mathrm{x}=0,0.4,0.7$, and 1) samples have different structures. So the substitution of Ti has greatly affected the phase structure of $\mathrm{MnBi}_{1-\mathrm{x}} \mathrm{Ti}_{\mathrm{x}}$ alloy. Figure 1 shows the characteristic intensity peaks of the LTP along with strong Bi peaks due to unreacted $\mathrm{Bi}$, for $\mathrm{x}=0$, and 0.4. Characteristic intensity peaks of $\mathrm{Mn}_{2} \mathrm{Ti}$ begin to emerge for $\mathrm{x}=0.7$ sample, and the sample is completely single $\mathrm{Mn}_{2} \mathrm{Ti}$ phase when the value of $\mathrm{x}$ is 1 ; meanwhile, both LTP and $\mathrm{Bi}$ peaks disappear in Fig. 1(d). Detailed analysis of the XRD pattern in Fig. 1(c) shows that the $\mathrm{x}=0.7$ sample

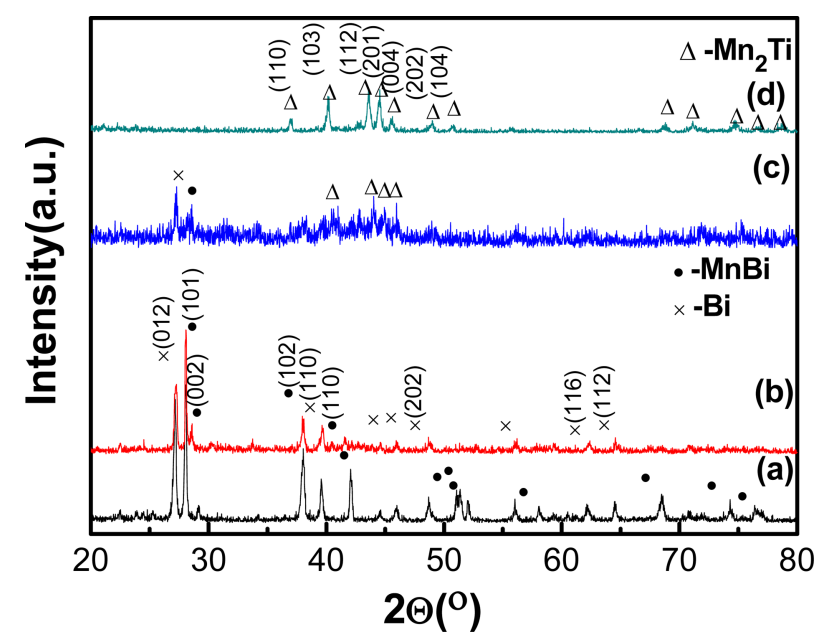

Fig. 1. (Color online) XRD pattern of the $\mathrm{MnBi}_{1-\mathrm{x}} \mathrm{Ti}_{\mathrm{x}}$ alloys, with (a) $x=0$, (b) $x=0.4$, (c) $x=0.7$, and (d) $x=1$. mainly contains four phases: low-temperature phase of $\mathrm{MnBi}$, Bi phase, $\mathrm{Mn}_{2}$ Ti phase, and a small amount of an amorphous phase. The intensity of the diffraction peaks for the $\mathrm{x}=0.7$ sample was lower than that of the $\mathrm{MnBi}$ sample. A higher background was found in the pattern of the $x=0.7$ sample. This suggests that the grain size was refined, as a consequence of the Ti substitution.

Figure 2 shows the temperature dependent magnetization for $\mathrm{MnBi}_{1-\mathrm{x}} \mathrm{Ti}_{\mathrm{x}}$ alloys for (a) $\mathrm{x}=0$, (b) $\mathrm{x}=0.4$, (c) $\mathrm{x}=0.7$, and (d) $x=1$ samples, in an applied field of 500 Oe. As shown in Fig. 2(a), with the increase of temperature, magnetization of $\mathrm{MnBi}$ alloy decreases slightly, reaches minimum value at around $497 \mathrm{~K}$, and then increases gradually up to $590 \mathrm{~K}$. Increase of magnetization with temperature is considered to be due to increasing the volume fraction of LTP $\mathrm{MnBi}$, which possesses a higher magnetization value [8]. The increase of magnetization above $500 \mathrm{~K}$ is due to the formation of the LTP of MnBi [14]. At $620 \mathrm{~K}$, the value of magnetization drops dramatically to nearly zero, which is due to the magnetic phase transition of $\mathrm{MnBi}$ from LTP to paramagnetic high-temperature phase (HTP) [15]. When the temperature decreases again after heating up beyond $670 \mathrm{~K}$, the magnetization retains a very small value down to $610 \mathrm{~K}$, then increases sharply with further decrease of temperature. This means that a large amount of LTP MnBi compound is again formed during the cooling down process. Temperature dependent magnetization measurements have been performed on other samples. Both Fig. 2(b) for $x=0.4$ and 2(c) for $\mathrm{x}=0.7$ have similar phase transition, compared to
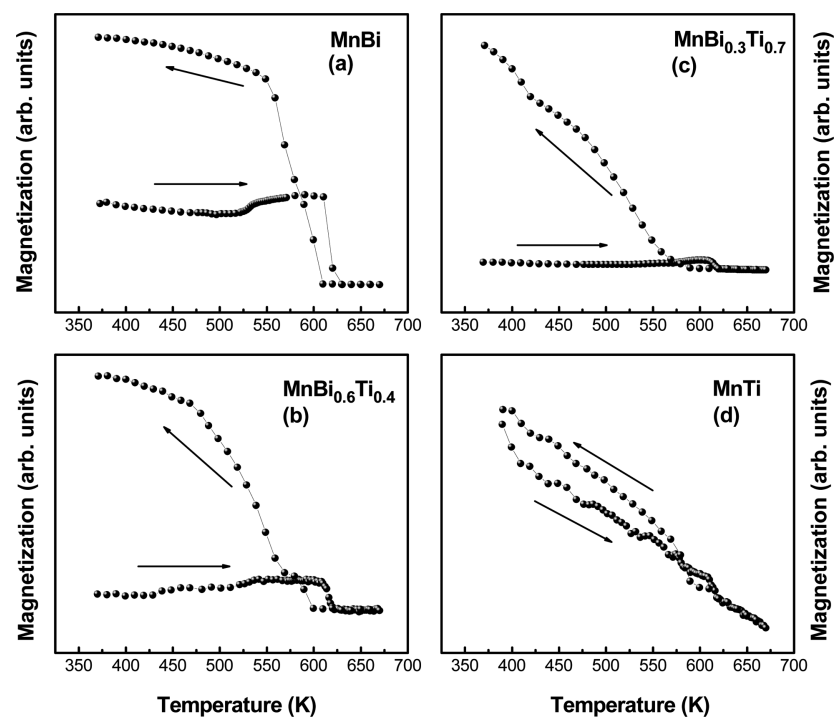

Fig. 2. Magnetization as a function of temperature in an applied field of 500 Oe for $\mathrm{MnBi}_{1-\mathrm{x}} \mathrm{Ti}_{\mathrm{x}}$ alloys, with (a) $\mathrm{x}=0$, (b) $\mathrm{x}=0.4$, (c) $\mathrm{x}=0.7$, and (d) $\mathrm{x}=1$. 

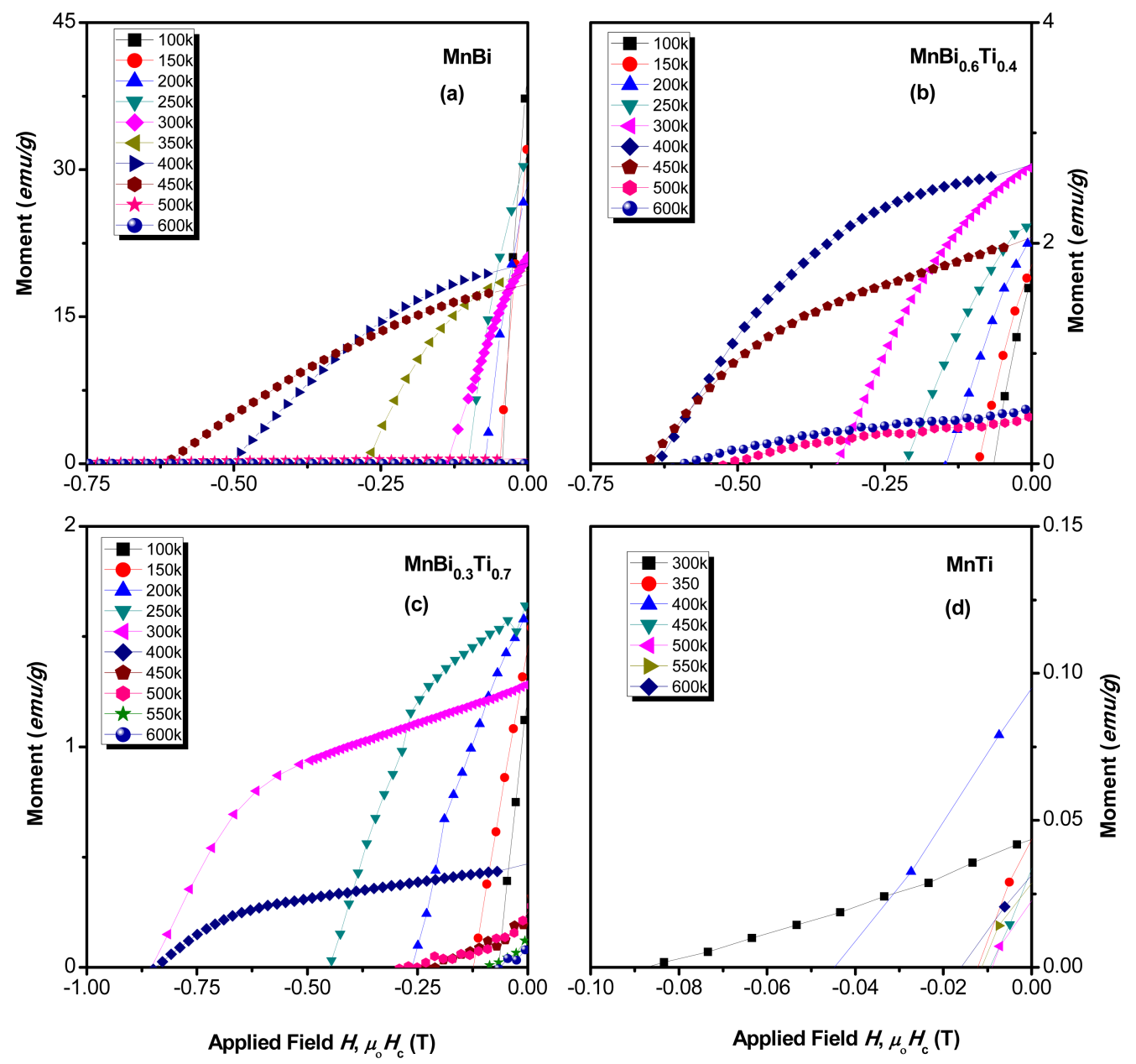

Fig. 3. (Color online) Demagnetization curve of $\mathrm{MnBi}_{1-\mathrm{x}} \mathrm{Ti}_{\mathrm{x}}$ alloys measured at different temperature, with (a) $\mathrm{x}=0$, (b) $\mathrm{x}=0.4$, (c) $\mathrm{x}=0.7$, and $(\mathrm{d}) \mathrm{x}=1$.

Ti free doped $\mathrm{MnBi}$ sample. In $\mathrm{MnBi}_{0.6} \mathrm{Ti}_{0.4}$ sample, the LTP-HTP and the HTP-LTP transition temperatures are $614 \mathrm{~K}$ and $599 \mathrm{~K}$, respectively. In $\mathrm{MnBi}_{0.3} \mathrm{Ti}_{0.7}$ sample, the LTP-HTP transition temperature is $612 \mathrm{~K}$, and the HTP-LTP transition temperature decreases to $589 \mathrm{~K}$. So the different phase transition temperatures are related to the content of $\mathrm{Ti}$ in $\mathrm{MnBi}_{1-\mathrm{x}} \mathrm{Ti}_{\mathrm{x}}$ alloys. In Fig. 2, the increase of magnetization with cooling, compared with that with heating, is most likely due to the formation of more LTP, as the sample passes through the heat treatment [16]. In MnTi sample, as shown in Fig. 2(d), magnetization decreases linearly as temperature increases, and vice versa. This coincides with structural transformation, and indicates that $\mathrm{MnTi}$ sample is a single $\mathrm{Mn}_{2} \mathrm{Ti}$ phase, and no phase transform has taken place while heating or cooling.

Figure 3 presents the demagnetization curves of the $\mathrm{MnBi}_{1-\mathrm{x}} \mathrm{Ti}_{\mathrm{x}}(\mathrm{x}=0-1)$ samples measured at different temperature. The coercivity of $\mathrm{MnBi}_{1-\mathrm{x}} \mathrm{Ti}_{\mathrm{x}}(\mathrm{x} \leq 0.7)$ alloys shows large temperature dependence, and exhibits a positive temperature coefficient. For each sample (except MnTi sample), the coercivity increases with temperature at first, and then decreases, as the temperature increases further. Both the coercivity and remanence value of MnTi sample are very small. That is due to no LTP being formed in the MnTi sample. This is in agreement with the former XRD results in Fig. 1(d).

Figure 4 shows the magnetic properties of the $\mathrm{MnBi}_{1-\mathrm{x}} \mathrm{Ti}_{\mathrm{x}}$ $(\mathrm{x}=0-1)$ samples. For Ti-free sample, with increasing temperature, its coercivity increases from $0.04 \mathrm{~T}$ at 100 $\mathrm{K}$, to a maximum value of $1.13 \mathrm{~T}$ at $550 \mathrm{~K}$; and then decreases to $0.95 \mathrm{~T}$, when the temperature gets to $600 \mathrm{~K}$ in Fig. 4(a). This coincides with what Ref. [17] reported. Variation of the coercivity with temperature is supposed to be controlled by the change of magnetocrystalline anisotropy. Therefore, the coercivity exhibits a positive temperature coefficient. The coercivity value of $\mathrm{MnBi}_{1-\mathrm{x}} \mathrm{Ti}_{\mathrm{x}}$ $(\mathrm{x} \leq 0.7)$ is higher than that of $\mathrm{MnBi}$ below $400 \mathrm{~K}$, 

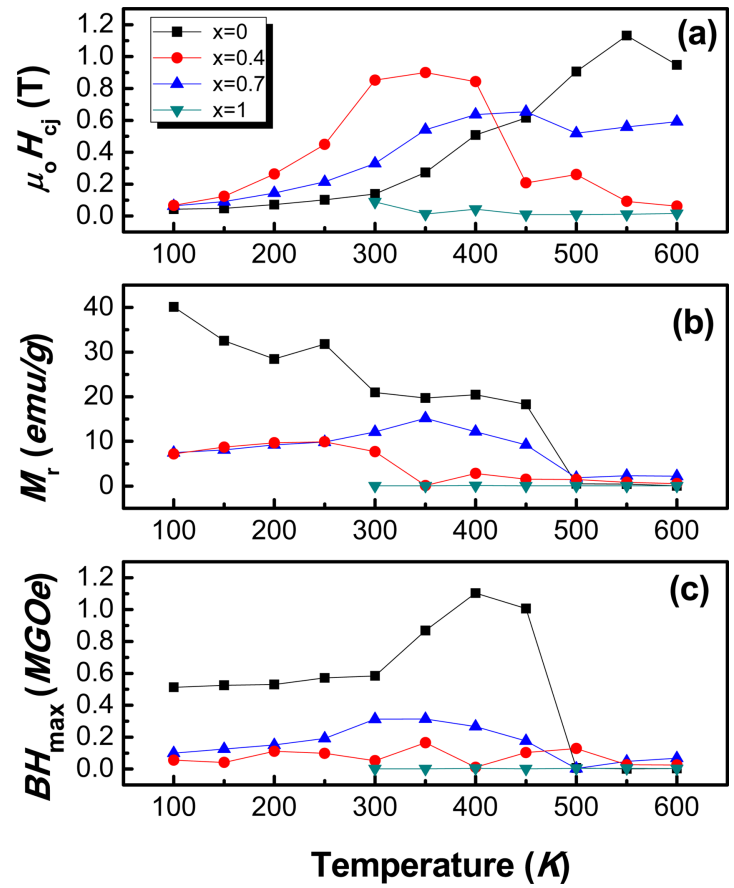

Fig. 4. (Color online) Temperature dependence of magnetic properties of $\mathrm{MnBi}_{1-\mathrm{x}} \mathrm{Ti}_{\mathrm{x}}$ sample.

according to the magnetic properties of different temperature. The results show that the optimal content of Ti for the coercivity of $\mathrm{MnBi}_{1-\mathrm{x}} \mathrm{Ti}_{\mathrm{x}}$ alloy is $\mathrm{x}=0.4$. As shown in Fig. 4(b), the remanence decreases gradually as the temperature increases, from $40.11 \mathrm{emu} / \mathrm{g}$ at $100 \mathrm{~K}$, to $18.30 \mathrm{emu} / \mathrm{g}$ at $450 \mathrm{~K}$; then decreases sharply to 0.51 $\mathrm{emu} / \mathrm{g}$, while the temperature increases to $550 \mathrm{~K}$. The value of remanence drops to nearly zero, when the temperature gets to $600 \mathrm{~K}$. This coincides with the LTPHTP transition at around $610 \mathrm{~K}$. For the MnTi sample, both coercivity and remanence remain at a very small value, in the temperature range from $300 \mathrm{~K}$ to $600 \mathrm{~K}$. When the temperature goes below $300 \mathrm{~K}$, its magnetic properties are out of the range that the Lakeshore 7407 can detect. This clearly demonstrates that no ferromagnetic phase is formed in the MnTi sample. Fig. 4 shows that substitution of $\mathrm{Ti}$ for $\mathrm{Bi}$ causes the coercivity rise below $400 \mathrm{~K}$. In part, this may be due to the refinement of grain size, and may partly be attributed to the strong pinning of the walls of the 'interaction domains' by the network of grain boundaries between the nanocrystalline grains [18]. Ti substitution has also changed the temperature dependence of coercivity. Guo et al. [19] presented a theory that relates the temperature dependence of the anisotropy field and coercivity. According to their theory, the anisotropy field is modified by Ti substitution for Bi. But the remanence and energy product show apparent decrease, with the addition of $\mathrm{Ti}$ in $\mathrm{MnBi}_{1-\mathrm{x}} \mathrm{Ti}_{\mathrm{x}}$ alloys; this may be caused by an increase in the amount of $\mathrm{Mn}_{2} \mathrm{Ti}$ phase. However, in doping samples, Ti substitutions in this lattice could be complicated. Therefore, investigation of the theory mechanism of Ti possibly occupying sites in $\mathrm{MnBi}_{1-\mathrm{x}} \mathrm{Ti}_{\mathrm{x}}$ alloys is in progress.

\section{Conclusion}

In conclusion, the microstructure and magnetic properties of $\mathrm{MnBi}_{1-\mathrm{x}} \mathrm{Ti}_{\mathrm{x}}(\mathrm{x}=0 \sim 1)$ arc-melting alloys have been measured and investigated, using X-ray diffraction (XRD) and vibrating sample magnetometer (VSM). The phase transitions between LTP and HTP MnBi have been analysed with heating or cooling, by measuring the temperature-dependent magnetization in $\mathrm{MnBi}_{1-\mathrm{x}} \mathrm{Ti}_{\mathrm{x}}(\mathrm{x} \leq$ $0.7)$ samples. The results indicate that the different phase transition temperatures are related to the content of $\mathrm{Ti}$ in $\mathrm{MnBi}_{1-\mathrm{x}} \mathrm{Ti}_{\mathrm{x}}$ alloys. MnTi samples are in $\mathrm{Mn}_{2} \mathrm{Ti}$ singlephase, with very low magnetic properties. Furthermore, below $400 \mathrm{~K}$, the coercivity increases, while the remanence and energy product decrease, with the substitution of $\mathrm{Ti}$ for $\mathrm{Bi}$ in $\mathrm{MnBi}_{1-\mathrm{x}} \mathrm{Ti}_{\mathrm{x}}$ alloys. The coercivity exhibits a positive temperature coefficient. The results show that the optimal content of $\mathrm{Ti}$ for the coercivity of $\mathrm{MnBi}_{1-\mathrm{x}} \mathrm{Ti}_{\mathrm{x}}$ alloy is $\mathrm{x}=0.4$. For $\mathrm{MnBi}$ sample, the coercivity reaches a maximum value of $1.13 \mathrm{~T}$ at $550 \mathrm{~K}$.

\section{Acknowledgments}

This work was supported by the National Science Foundation (no. 51371163, 51301158), Zhejiang Province Innovative Research Team (2010R50016), Provincial Major Science and Technology Project of Zhejiang (2012C010315), Education Department Scientific Research Project of Zhejiang Province (Y201329502), and National Public Research Project Special for Quality Testing (201210107).

\section{References}

[1] C. Guillaud, J. Phy. Radium 12, 143 (1951).

[2] W. E. Stutius, T. Chen, and T. T. Sandin, AIP Conf. Proc. 18, 1222 (1974).

[3] D. Chen and Y. Gondo, J. Appl. Phys. 35, 1024 (1964).

[4] J. B. Yang, W. B. Yelon, W. J. James, Q. Cai, S. Roy, and N. Ali, J. Appl. Phys. 91, 7866 (2002).

[5] S. Saha, R. T. Obermyer, B. J. Zande, V. K. Chandhok, S. Simizu, and S. G. Sankar, J. Appl. Phys. 91, 8525 (2002).

[6] P. Y. Zhang, R. Hiergeist, M. Albrecht, K.-F. Braun, S. Sievers, J. Lüdke, and H. L. Ge, J. Appl. Phys. 106, 073904 (2009). 
[7] D. T. Zhang, S. Cao, M. Yue, W. Q. Liu, J. X. Zhang, and Y. Qiang, J. Appl. Phys. 109, 07A722 (2011).

[8] H. Yoshida, T. Shima, T. Takahashi, and H. Fujimori, Mater. Trans., JIM 40, 455 (1999).

[9] J. Zhou, I. A. Al-Omari, J. P. Liu, and D. J. Sellmyer, J. Appl. Phys. 87, 5299 (2000).

[10] W. Y. Zhang, A. R. Yan, H. W. Zhang, and B. G. Shen, J. Alloys Compd. 315, 174 (2001).

[11] Z. Yao, C. B. Jiang, Structure and Magnetic Properties of $\mathrm{SmCo}_{\mathrm{x}} \mathrm{Ti}_{0.4}-1: 7$ Ribbons, J. Magn. Magn. Mater. 320, 1073 (2008).

[12] D. Nagahama, T. Ohkubo, T. Miyoshi, S. Hirosawa, and K. Hono, Acta Mater. 54, 4871(2006).

[13] N. J. Harrison, H. A. Davies, and I. Todd, J. Appl. Phys. 99, 08B504 (2006).
[14] S. Saha, R. T. Obermyer, B. J. Zande, V. K. Chandhok, S. Simizu, S. G. Sankar, and J. A. Horton, J. Appl. Phys. 91, 8525 (2002).

[15] Y. B. Yang, X. G. Chen, S. Guo, A. R. Yan, Q. Z. Huang, M. M. Wu, D. F. Chen, Y. C. Yang, and J. B. Yang, J. Magn. Magn. Mater. 330, 106 (2013).

[16] S. Saha, M. Q. Huang, C. J. Thong, B. J. Zande, V. K. Chandhok, S. Simizu, R. T. Obermyer, and S. G. Sankar, J. Appl. Phys. 87, 6040 (2000).

[17] X. Guo, X. Chen, Z. Altounian, and J. O. Stromolsen, J. Appl. Phys. 73, 6275 (1993).

[18] C. B. Jiang, M. Venkatesan, K. Gallagher, and J. M. D. Coey, J. Magn. Magn. Mater. 236, 49 (2001).

[19] X. Guo, X. Chen, Z. Altounian, and J. O. Ström-Olsen, J. Appl. Phys. 73, 6275 (1993). 